\title{
Semantics, Ontologies and Information Systems in Education: Concerns and Proposals
}

\author{
Antonio Cartelli \\ Faculty of Humanities, University of Cassino \\ Cassino (FR) Italy
}

cartan@unicas.it

\begin{abstract}
The author describes his experience with students interacting with some websites he made for didactics and research and how this led him to an appreciation for the need for better searching tools and strategies for education. The students' difficulties emerging from the above observations were a special case of the more general problem evidenced from people while searching information on the web. Semantic web is then discussed as a way to help people overcome their difficulties in using the web to gain knowledge.

The paper describes some models for knowledge construction and analyzes them in terms of their suitability as instruments for the introduction of semantics on the web. The paper then provides evidence regarding some limits for the systematic use of semantic search engine and ontology domain systems in everyday teaching and knowledge construction.

Finally, the paper reports and explains a hypothesis of an information system for building communities of practice and letting them work on the construction of domain ontology. The paper concludes that this construct is well adapted to the model for knowledge construction firstly hypothesized, and can give good results in teaching-learning planning and carrying out and in helping scientists and scholars to analyze scientific paradigms and to find new trends for research.
\end{abstract}

Keywords: information system, knowledge construction, learning objects, ontology, semantic web, units of learning

\section{Introduction}

More and more, Higher Education (both in high school and University) are benefiting from the Internet and its resources. A variety of systems are used to support teaching-learning activities in the school and the university and to satisfy lifelong learning needs, mostly with the help of the Web. Examples of these systems are: Content Management Systems (CMS), Learning Management Systems (LMS) and Computer Supported Collaborative Learning Systems (CSCLS) (Tren-

Material published as part of this publication, either on-line or in print, is copyrighted by the Informing Science Institute. Permission to make digital or paper copy of part or all of these works for personal or classroom use is granted without fee provided that the copies are not made or distributed for profit or commercial advantage AND that copies 1 ) bear this notice in full and 2) give the full citation on the first page. It is permissible to abstract these works so long as credit is given. To copy in all other cases or to republish or to post on a server or to redistribute to lists requires specific permission and payment of a fee. Contact Publisher@InformingScience.org to request redistribution permission. tin, 2004). The first two types of systems are primarily content oriented (i.e., scientific and disciplinary topics and teaching-learning activities are their main focus); the last type of system is based on social and situated learning experiences and uses ICT to let students communicate and build social environments for knowledge construction. Furthermore, the comparison of the features of different e-learning platforms (both 
open source and proprietary) and the evaluation of their performances (Colace, De Santo \& Vento, 2003; Graf \& List, 2005) shows the importance of systems having all the above features to the success of e-learning contexts in education.

It is also important to note that analysis and explanation of knowledge construction and evolution have great relevance not just for education; corporate and firms are, in fact, strongly interested in the creation of systems for the capture, analysis and development of knowledge and skills, both on an individual and a social basis (communities of practices). The motivation for this interest is the increase in the acquisition of new markets and good performance that organizations can achieve by means of knowledge discovery and knowledge audit systems, knowledge mapping systems, decision support systems, data warehouse and data mining systems, or, in other words, by means of knowledge management systems.

Finally, it has to be noted that special problems or particular needs that emerge in disciplines and in scholars' studies and research can lead to the creation of Web sites and systems for the management of data, information and knowledge. These systems, which are usually self made and can be based on the use of proprietary and/or open source general purpose software, have a relevant place in the management of scientific knowledge together with the above well structured and suitably made platforms.

This paper describes the structure of a web site of this kind and the analysis and results of the teaching-learning experiences the author carried out with it.

\section{The Experience of the Web Site "Didactical Materials for Latin Paleography"}

The "Didactical Materials for Latin Paleography" web site was planned and implemented to let students attending Latin paleography lessons easily access and use various kinds of didactical materials (Cartelli \& Palma, 2005). It consists of three sections, which are described below, and is still evolving and growing by addition of different documents. Within it one can find:

a) plates, reproducing charters in ancient manuscripts (texts written in the various Medieval scripting styles). Together with these images, their translations are reported (i.e., digital full texts where symbols, special signs and abbreviations are clearly written). All documents are organized on the basis of the scripting style used for the plates.

b) texts, containing full or partial documents reproducing papers, presentations and articles on different discipline topics, such as book archeology, scripting styles (e.g. beneventana, cancelleresca, carolina, gotica, mercantesca, umanistica), cataloguing, history of paleography etc.

c) works in progress, where special documents are placed; they are mostly devoted to work group experiences. These documents are in fact managed by all students attending the course and collect their exercises, analyses and suggestions.

The first and third sections contain materials to be used mostly for everyday work; in the second section texts mostly used for the professor's lectures can be found. New plates and texts are continuously inserted in the site for the enrichment of the scripting reference examples or for reporting the results of studies and research. Texts are summarized or extracted from books and proceedings of conferences and are made available with the authors' approval. Recently there has been an increase in the number of scholars and researchers who propose papers to be published in the site. (Many documents come, in fact, from national and international conferences and are made available only for didactical purposes). 
The system was created in 2001 and has been used since then by Professor M. Palma to support his lectures and manage his everyday teaching. On the other hand, while involved in the construction of the site, the author of the paper could analyze and study students' behaviors when they interacted with this new system and could observe how their ways of using site materials changed over time. This last work was very easy to accomplish due to the small number of students involved each time in running of the course. (The academic year 2002-2003 had the biggest class with 19 students attending the lessons. In other academic years, there were from 6 to 17 students attending the lessons.)

The analysis of students' behaviors and the results coming from the use they made of other didactic sites concerning ancient manuscripts led the author to hypothesize the relevant effects of those instruments on the construction of special communities and on the development of new knowledge and skills (Cartelli, 2005b; Cartelli \& Palma, 2004, 2005).

We note that how students' accessed didactic materials in the site has changed over time:

a) the students accessing the site in its first stage (i.e., when it was created and there were only a few documents within it), usually read all available texts and did this on their own,

b) now, with more than 72 documents and 211 plates (with their translations) available in the site, students mostly limit their reading to the texts the teacher suggests during the lessons and do this only when they are explicitly invited to do so.

When asked for the reason for their behavior, most of the students state they have difficulty in finding the "right documents" to study or to analyze; in other words, they explain, when they need some information for solving a special problem or studying a particular topic, they go to the site, try to locate the right section, and start reading the document they suppose to be useful. Very often they are forced to read more than one document before finding the right information and, sometimes, this time consuming job prevents them from ending the research and finding what they were searching for. Students experience this difficulty despite the site tree structure (reproducing the structure of the discipline topics), the index pages clearly indicating the available texts, and the systematic use of thumbnails (icons) for giving a preview of plates and other images.

A short survey made at the beginning of the academic year 2005-2006 on a class of 12 students (before lessons started) led to the same results. The students were given a limited time and instructed to browse the site to find documents concerning one or more special topics that were suggested by the professor. Only $25 \%$ of them successfully found the right pages in the appointed time, $42 \%$ found them after the deadline and 33\% did not succeed in finding them and stopped their research after having looked through only a few pages. Table 1 shows the number of students with the percentages.

Tab. 1 - Distribution of students successfully accessing the right pages in the site

$\begin{array}{lcc}\text { Success in accessing the right document in a fixed time } & \text { N. of students } & \text { \% } \\ \text { Succeeded before the deadline } & 3 & 25 \% \\ \text { Succeeded after the deadline } & 5 & 42 \% \\ \text { Didn't succeed in finding the right document } & 4 & 33 \%\end{array}$

\section{Further Analyses}

The situation described in the above paragraph for the students of paleography seems very similar to a more general question: what kind of difficulty do people encounter while searching materials on the Web? Do they succeed in finding the right data they are searching for? How long and stressful is the searching job? 
When search engines were first introduced in the web, people thought that the finding of information would be very easy and that all the above problems were solved. Now, with the increase of the amount of information and the growth of the number of search engines (very different among themselves for their features), we know that things are not so easy and the above problems are far from being solved. The main reason for the difficulties that are reported is the fact that word matching (actually used all over the web to find HTML pages) doesn't guarantee the right result for a given search.

Recently, because of its features, the semantic web has been proposed to offer a good solution to the problem.

To give the semantic web a pedagogical perspective, within which to consider the effects the web can have on individuals' knowledge construction and development, two themes will be deeply analyzed in the following paragraphs: 1) instruments for giving semantics to the web and their possible educational application, 2) models for knowledge construction and evolution in mankind and their consistency with the semantic web.

\section{Semantic Web and Pedagogy}

Until now the basic idea of the semantic web has been relatively straightforward: to let the web evolve to enable the automatic processing of its content so that data can be shared and processed both by humans and software (Berners-Lee \& Fischetti, 1999; Berners-Lee, Hendler, \& Lassila, 2001).

To reach this goal requires instruments and strategies for enabling computers to 'understand' web pages. Users can then be helped in searching for relevant information, in making inferences and calculations, and in combining information in new ways. The reverse side of the coin is that authors must provide explicit and domain specific meaning ('semantics') to allow automatic machine-interpretation.

Today there are several technologies for the semantic web and they are reported and analyzed below:

1. Latent Semantic Analysis (Landauer \& Dumais, 1997) is based on programs which can understand natural language so that humans are no longer forced to provide semantic meaning to information (i.e., to type meta-data and use artificial coding schemes). It provides a kind of factor analysis analyzing data (texts) and ordering them on a given underlying dimension; new text can be interpreted by mapping it on the domain specific underlying dimensions it was extracted from (i.e., it provides the interpretation of the meaning of words)

2. OWL (Ontology Web Language) is used when the information in the documents has to be processed by applications, as opposed to the situation where the content has only to be presented to humans. Ontology languages provide machine interpretability of Web content much more than XML, RDF, and RDF-Scheme; this result is obtained by the addition of vocabulary and formal semantics to web content (McGuinness \& Van Harmelen, 2003). In other words OWL implements a semantic description of a certain domain by specifying its concepts (terms in vocabularies) and the relationships between them. It has three increasingly-expressive sublanguages: OWL Lite, OWL DL, and OWL Full

3. RDF and RDF-Scheme is the metadata approach from the W3C (RDF, 2003). It does not structure the syntax of the data, but defines semantic meaning for data on the web. Multiple semantic perspectives of the same data are possible. It is based on two lower level technologies: URIs to identify web resources and Namespaces to identify different vocabularies. 
4. Software Agents (Jennings, 1998). These are usually regarded as software pieces that can act proactively, can be adaptive and (semi-) autonomous and can communicate with other agents and with their human creators. In other words software agents can be identified with all computer programs which can read and process the coded semantics in the data to help humans to perform their tasks more efficiently and effectively.

5. Topic Maps provide an alternative technology to RDF (Cover, 2003). They let users define arbitrarily complex semantic knowledge structures and allow the exchange of information for collaboratively building and maintaining indexes of knowledge. They provide a more general approach to semantics in documents than RDF, basically because they are not limited to web environment.

6. Unified Modeling Language (UML) (Fowler, 2000) provides a collection of models and graphs for the description of the structural and behavioral semantics of any complex information system. Some of the elements provided are: a) case models and scenarios capturing the user requirements and functionalities of the system (scenarios are instances of cases), b) class and object diagrams specifying the semantic information structure of a system (object diagrams are instances of class diagrams), c) activity diagrams describing workflows, d) state diagrams showing the dynamic behavior of an object in a system, e) interaction diagrams (sequence and collaboration diagrams) modeling collaboration among groups of objects, f) physical diagrams (deployment and component diagrams) simulating the structure of a system.

7. XML and XML Schemes are derived from SGML (XML, 2003). They are used to go beyond the fixed, page structure, oriented vocabulary of HTML. They can structure data and documents according to personal or community defined vocabularies. These vocabularies can have a semantic nature and support the open exchange of data among the communities and tools understanding them.

While looking at the use of the above instruments in teaching and learning activities R. Koper (2004) systematically analyzed the trend in instructional design deriving from their use. He stated that the introduction of the above instruments in education aimed at: (a) increasing the effectiveness of education, (b) increasing the flexibility and accessibility of education, (c) increasing the attractiveness of education and (d) decreasing the workload for educational staff (or more in general: decreasing the institutional costs). On this basis he proposed an educational semantic web, i.e., a strategy representing a course in a formal, semantic way so that it could be interpreted and manipulated by computers as well as humans.

A deeper discussion of Koper's proposals is beyond the scope of this paper, but the following remarks describe, in the author's opinion, some problems and limits in the adoption of semantic web in education as it emerges from the proposals reported as of now:

1. First, it is very difficult to find a correspondence between the representation of knowledge emerging from the use of the instruments described above (building semantics in the web) and the constructivist models for knowledge development reported in the first section (and in the subsequent one); in other words, there is a great difference between knowledge representation and knowledge construction, and the history of last decades with the results of the studies on misconceptions and mental schemes clearly supports this difference (Cartelli, 2003)

2. Second, the use of semantic web for the representation of scientific knowledge introduces less flexibility and adaptability in knowledge evolution and in scientific paradigmatic changes, like the ones hypothesized from Kuhn (1969) in his theory of scientific revolutions. Ontologies and the semantic web more in general, in the author's opinion, create a 
static representation of human knowledge, because they represent objects and relations among themselves as they exist at a given moment and they adapt very difficultly to the changes induced by new emerging ideas. If new scientific paradigms are needed for interpreting phenomena the only way to represent them in a given semantic structure is the creation of a new structure (a new ontology).

\section{Knowledge Development Models, ICT and Teaching: A Survey}

Human knowledge has been studied since mankind's origins. First of all, philosophy has played a relevant role in interpreting human knowledge; later, especially during the last century, human sciences intervened in explaining phenomena both on an individual and a social perspective. Nowadays many scholars look at constructivist hypotheses as the more suitable ones for the explanation of knowledge construction and evolution in people interpretation of phenomena.

Together with the numerous theories on human knowledge many models for its construction and evolution have been developed over time. In what follows a special model will be analyzed in greater detail, not only because it is very recent, but also for the relevance that ICT plays in it. Figure 1 shows the tri-partition of knowledge phenomena in the model; it shows the importance that different levels of human socialization have on knowledge construction (Cartelli, 2006).

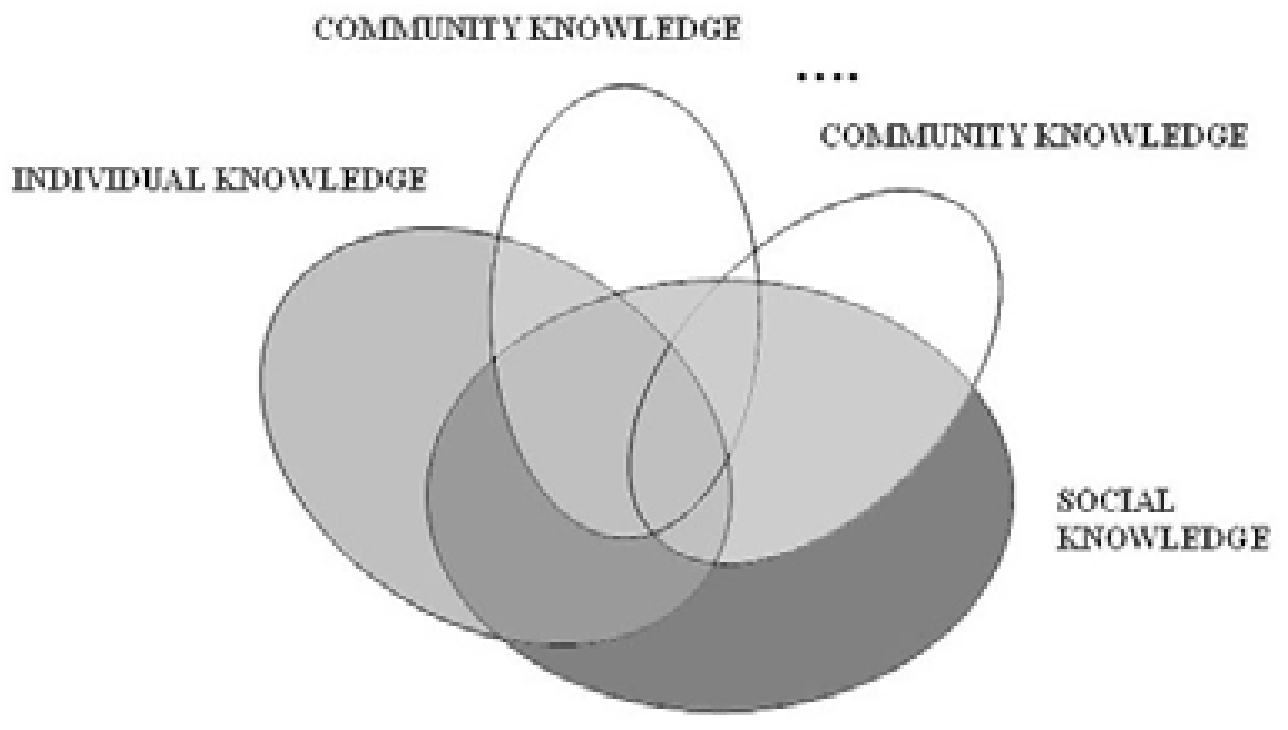

Fig. 1 - Hypothesis for the structure of human knowledge

There are at least three different kinds of knowledge in the model:

a) individual or personal knowledge, i.e., the knowledge a subject has and builds at a given moment, due to his/her interaction with reality.

b) community knowledge, i.e., the knowledge resulting from the interaction of the members of a community; it is the sum and the expression of the know how and the best practices of all the subjects in the community. This kind of knowledge can be identified with the knowledge of a special entity, the community, as it behaves autonomously (maybe differently) from all the subjects it is made of. 
c) social knowledge or culture, i.e. the expression of the history and tradition of the society the subjects belong to. Among various elements in this type of knowledge scientific and discipline knowledge play a special role. Subjects and communities can propose new theories and ideas both on the basis of theoretical analyses and experimental results, but sciences in their entirety cannot be considered knowledge constructions of subjects and communities; all ideas and theories in a discipline must be included in commonly accepted scientific paradigms. In other words scientific ideas must be approved from the scientific community to be valid, and only this last step gives them the absolute and objective features and lets them be universally accepted (i.e., lets them become part of human culture).

The main effect of the above tri-partition is, in the author's opinion, the presence of three different ways for knowledge construction:

a) personal interaction with reality and consequent construction of mental schemes for phenomena interpretation (interactive constructivism explains them in several different ways).

b) social interaction among the subjects in a community under the well known E. Wenger's (2004) conditions: 1) presence of a shared identity domain, where membership implies a commitment to the domain, and therefore a shared competence that distinguishes members from other people; 2) community, because in pursuing their interest in their domain, members engage in joint activities and discussions, help each other, and share information; 3) practice, because members of a community of practice are practitioners; they develop a shared repertoire of resources: experiences, stories, tools, ways of addressing recurring problems. These features have been usually assigned to communities of practices but have also been found in communities of learners, fostered communities of learners, virtual communities (Cartelli, 2005a).

c) construction of social models by the subjects immersed in the society and by their living in it, and construction of well structured discipline knowledge (as the highest form of identification of the subjects with the society); school (at all levels) plays a great role in this last way of building knowledge, because it transmits discipline topics to students together with well suited and commonly accepted behavioral models.

It is perhaps too early to say if the above model has the right requisites to be adopted for the description of all knowledge phenomena and for the planning and carrying out of teaching-learning activities. Nevertheless, the increase in the importance of informal education (coming, for example, from subjects' interaction with media, IT and ICT) with respect to formal and non-formal education (school, association etc.), and the influence of other factors all depending from complexity of today society, are showing the inadequacy of old educational models with respect to knowledge society needs. The experiments for the finding of new didactical strategies and the proposal of new regulations for schools all over the world are a good proof, in the author's opinion, for the new emergence in education.

In what follows, two different situations exploring the compatibility of the above model with different contexts explaining knowledge construction are reported.

As regards pedagogical and didactical research it can be stated that the following experiences and theories all agree with the above model:

a) the use of individual and social constructivist strategies in education (Varisco, 2002),

b) the construction of communities of learners or the fostering of communities of learners (Scardamalia \& Bereiter, 1996) 
c) social knowledge theory (Wenger, 1998).

As regards the impact of ICT on knowledge phenomena and its compatibility with the above model two types of conclusions become possible:

a) when looking at knowledge phenomena from a constructivist perspective the above model can be applied to all contexts: individual, community and society, and succeeds in explaining them.

b) when the application of ICT in education is analyzed and special e-learning experiences are discussed different situations emerge:

- learning objects (LOs), usually adopted for managing students' interaction with discipline structure, have only the individual and the social (scientific) knowledge units as reference element in the model, - units of learning (UOLs), which implement learning activities within the learning objects (Koper, 2001), have both the individual and the social units of the model as reference elements

- Computer Supported Collaborative Learning Systems (CSCLS) and all e-learning platforms implementing synchronous and asynchronous communication instruments and strategies to support communities of learners (or of practice), have the community unit of the model as reference element - semantic web and domain ontologies directly refer to scientific (social) knowledge as the corresponding unit of the model.

The main consequence of the above considerations is once again the difference between knowledge representation and knowledge construction. It is clear that when passing from knowledge representation to its construction, of the above instruments no single one is transversal to the model discussed above (i.e., none can be adopted for all the knowledge construction units in the model).

\section{Semantic Web and Information Systems}

In one of the above sections it was mentioned that the semantic web, and ontology systems with it, can synthesize and represent knowledge in a given domain with all the concepts and the relations existing among themselves. Furthermore it has been shown that as regards the planning and carrying out of effective didactical activities and the help that people can receive in building the right and meaningful knowledge, there are two different positions on those systems:

1) they are supposed to help teachers in their everyday work due to their features;

2) they don't meet the features of a special knowledge construction and development model and further studies are needed for finding the better way for their introduction in teaching-learning activities.

On the other hand, it has to be noted that information systems never appear among the instruments leading to semantic web also if, in the author's opinion, they can play a relevant role both in introducing semantics in the web and in building effective educational experiences. At the basis of this hypothesis are two kinds or arguments:

a) the experiences the author had with on line information systems (dynamic web sites interfaced with databases), which led to the construction of communities of learners and of practices, and confirmed the structure of the model reported in the above section,

b) the increased awareness of the importance of human interaction with automatic systems for data analysis and management on the web. 
With respect to the hypotheses reported up to now, this new idea assigns a great role to humans and to the implementation of their interaction processes for the construction of a domain ontology and semantic web with respect to the strategies for automatically represent scientific information.

In other words, in the author's opinion, a suitable information system, with its databases and selected accesses, can create a semantic network on a given knowledge domain (based or not on pre-existing web pages or any kind of document and bibliography) while integrating in itself the knowledge construction model reported above. The proposal of such an information system letting individuals, communities and disciplines (sciences) analyze and create knowledge follows.

\section{The Information System}

As usually happens with all information systems the explanation of the whole project and the description of the system itself both involve the following elements: a) data and their structure, b) subjects and their interactions, c) data flow and processes description.

As regards data (to be managed by a RDBMS) the following elements are hypothesized:

a) system administrator/s, who can create accounts for scientific administrators and students/contributors and manage all information and data in the database,

b) scientific administrator/s, who assign scientific topics to students/contributors for the management of data (compilation of entity and relationship cards) and verify the correctness of the work made by contributors (they are entrusted with the task of validating compiled cards),

c) students/contributors, containing personal data of people cooperating to the construction of the system (including identification and access data; i.e., ID code and password),

d) entities, where concepts, instruments, people, places and times, concerning the topics in the knowledge domain, can be found,

e) relationships, where the links between entities are included; they also contain the description of the links and the references to documents, they can be mono-directional or bidirectional (depending on the type of the connection between entities),

f) reference cards, with data concerning any kind of document (both in printing or on the web) and the links to the documents available in the site (or elsewhere in the web),

g) communication, an electronic blackboard letting people exchange messages in selected ways; i.e., on the basis of the topics they are interested in and in a more general way.

The users accessing the data base have different rights and powers:

a) the user with the least rights on the data is the one who can only query the system to obtain the map of the knowledge domain, the list of available topics, their descriptions and the links to bibliographic materials,

b) at an upper level are the students/contributors who can access a special Web area (by means of their ID and password) with a menu of the allowed operations, i.e. they can see the topics the administrator/s assign them, can manage entity cards, relationship cards and bibliographic cards,

c) the scientific administrator/s follow, they can manage all the data in the data base and write, modify and certify the entity, relationships and bibliographic cards, also if this last operation can be done only once (i.e. when the cards are verified they can no more be accessed from the administrator/s), 
d) at the top of the access pyramid is the system administrator who can do all the operations allowed to the scientific administrator/s and can access the verified cards to modify or to delete them.

Once the entity and relationship cards are compiled from the students/contributors and verified from the scientific administrator/s they can be queried from a generic user. People interested in the information contained in the data base and in accessing the ontology domain have two different query systems. First, they have a page containing most relevant topics in the domain; if they select one of the items they find a description of the topic and of the links to related arguments, instruments, people etc. For each element they have in the same page parent and descendant concepts and can browse the discipline tree. Second, they have a traditional search system letting them find pages by means of special fields or terms within them.

When the system starts the data base is empty, and the system administrator has to input the data for at least a scientific administrator. When a scientific administrator is enabled he/she can input the data for one or more students/contributors and make them access the system; he/she can also input the topics to be chosen/assigned to the contributors and can input by him/herself the entity, relationship and bibliographic cards. When the contributor/s can access the materials to work on they can compile the cards. Finally the cards are analyzed and revised from the administrator/s so that they can be read by general users. Figure 2 shows what the various users can do.

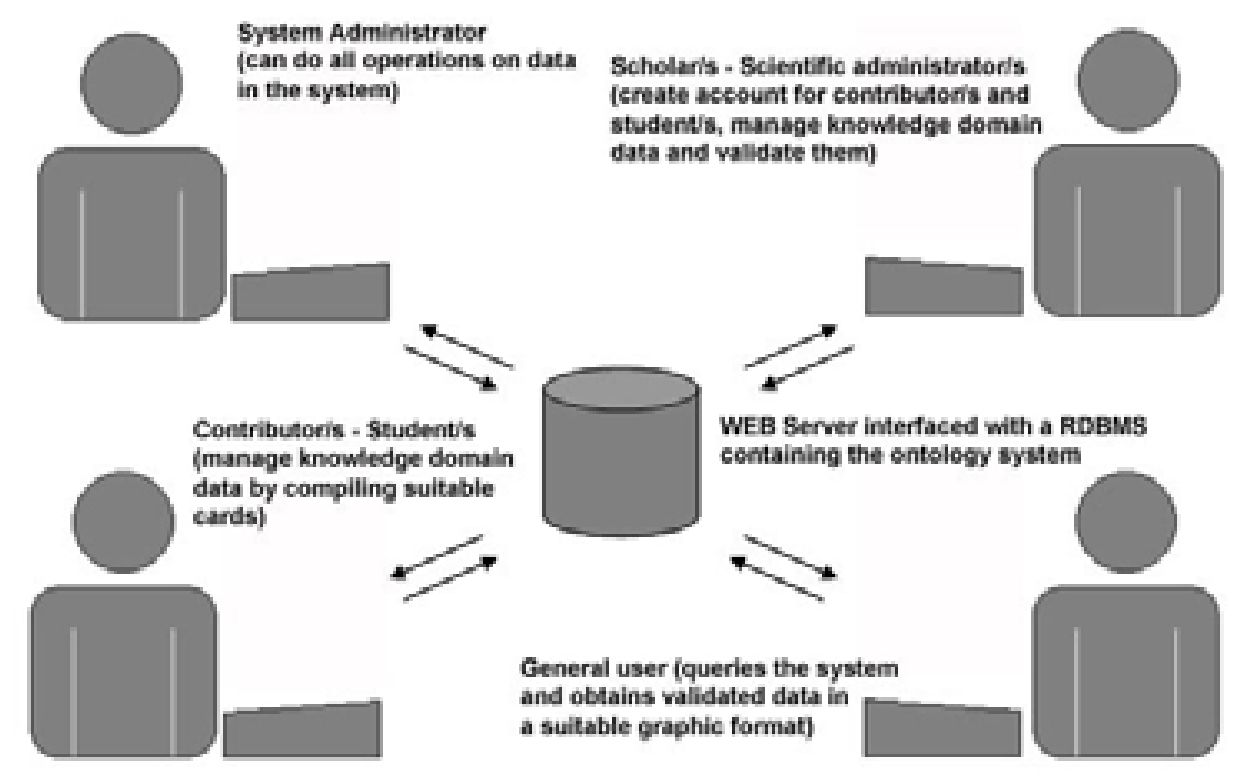

Fig. 2 - Users accessing the system and authorized operations

The key for the success of this system is in the communication subsystem (the electronic blackboard), letting people involved in the creation of the database share their experiences and knowledge, finding support and help from better skilled subject, and so on.

As can be easily shown, the system agrees with the knowledge construction model discussed in the above sections: individual, community and social (science) components of the model are in fact interested in the knowledge construction and evolution process.

Figure 3 synthesizes knowledge construction at the three different levels: individual, community and society. 


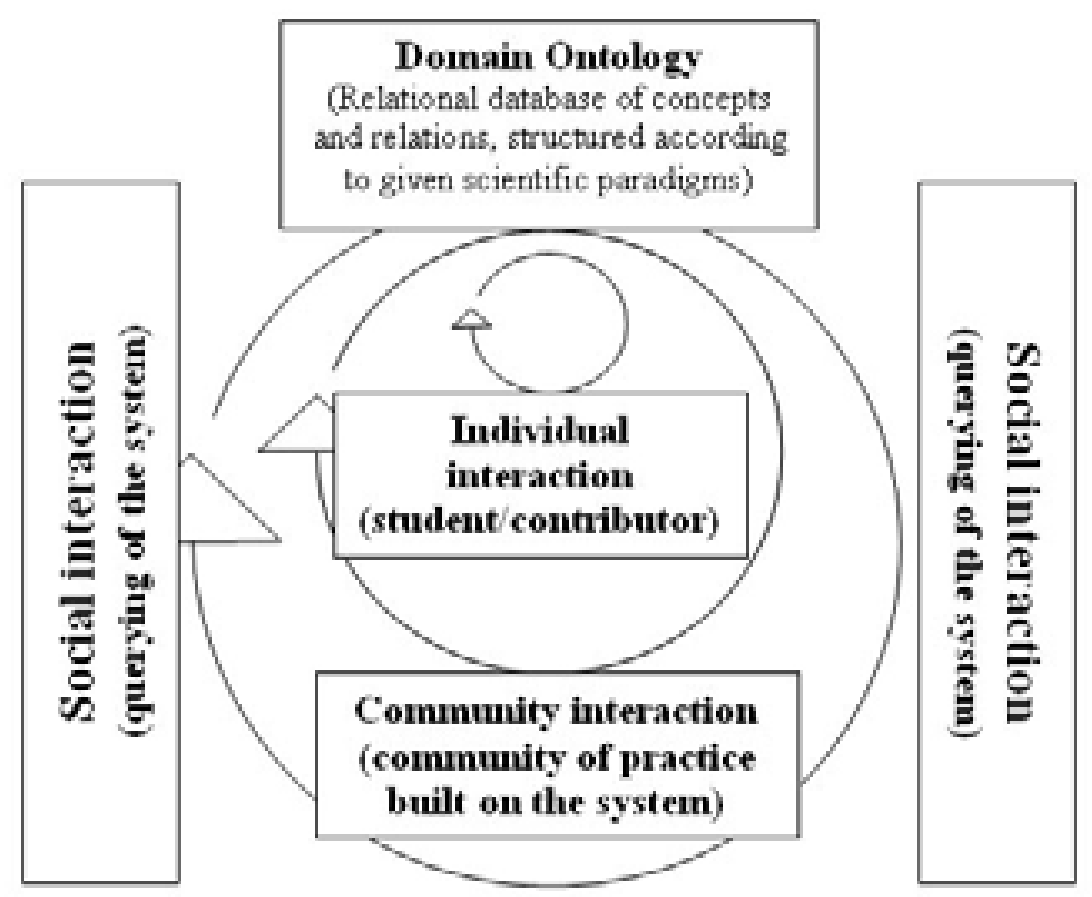

Fig. 3 -Model of knowledge construction accor ding to system's access

\section{Conclusion}

Introducing semantics into the web for automatic representation of knowledge is no easy task. But it can be very useful in education for its continuous involving subjects at all their levels of knowledge construction.

The author's experiences led to an information system around which communities of learning and of practices were built. The results of the experiences up to now agree with the knowledge construction model reported in the paper; they led to the introduction of a new element in the SECI knowledge evolution model by Nonaka and Takeuchi (1995) and showed the importance of social-constructivist instruction strategies in today education.

As a conclusion it seems possible that the hypothesized system will be useful for improving teaching-learning strategies even if it will not lead to the automatic management of documents on the Web.

\section{References}

Berners-Lee, T., \& Fischetti, M. (1999). Weaving the Web: The original design and ultimate destiny of the World Wide Web by its inventor. San Francisco: Harper.

Berners-Lee, T., Hendler, J., \& Lassila, O. (2001). Il Web Semantico. Quando Internet diventa intelligente: agenti software e rappresentazioni condivise per un'automazione dei servizi in rete ... e a casa nostra. Le Scienze (Italian edition of Scientific American), May (393), 77-84.

Cartelli, A. (2003). Misinforming, misunderstanding, misconceptions: What informing science can do. In (E. Cohen, E. Boyds ed.s) Proceedings of IS + IT Education 2003 International Conference, pp. 12591273. Retrieved on line March 5, 2006 from: http://proceedings.informingscience.org/IS2003Proceedings/docs/156Carte.pdf 
Cartelli, A. (2005a). TIC, comunità di apprendimento e modelli di sviluppo della conoscenza. Journal of eLearning and Knowledge Society, 1 (1), pp. 75-88.

Cartelli, A. (2005b). ICT and Knowledge Evolution in Learning Organizations the Lesson from Paleographers' Community of Learners. In (F. Malpica, F. Welsch \& A. Tremante ed.s) Proceedings of EISTA International Conference, Vol. 2, pp. 275-280. Orlando (FL): IIIS.

Cartelli, A. (2006). ICT, Knowledge Construction and Evolution: Subject, Community and Society. In (A. Cartelli ed.) Teaching in the Knowledge Society: New Skills and Instruments for Teachers, pp. 33-53. Hershey (PA): Idea-Group Inc.

Cartelli, A., Palma, M. (2004). BMB On Line: An Information System for Paleographic and Didactic Research. In (M. Khosrow-Pour ed.), Proceedings of IRMA 2004 International Conference: "Innovation Through Information Technology", Vol. 1, pp. 45-47. Hershey (PA): Idea-Group Inc.

Cartelli, A., Palma M. (2005). Computer and Information Systems in Latin Paleography Between Research and Didactic Application. In (D. Carbonara ed.) Technology Literacy Applications in Learning Environments, pp. 288-298. Hershey (PA): Idea-Group Inc.

Colace, F., De Santo, M., \& Vento, M. (2003). Evaluating On-line Learning Platforms: a Case Study. In Proceedings of the 36th Hawaii International Conference on System Sciences (HICSS'03), retrieved on line March 05, 2006 from http://csdl2.computer.org/comp/proceedings/hicss/2003/1874/05/187450154c.pdf

Cover, R. (2003). (XML) Topic Maps. Retrieved December 11, 2004, from http://xml.coverpages.org/topicMaps.html

Fowler, M. (2000). UML distilled (second edition). Upper Saddle River (NJ): Addison-Wesley.

Graf, S., \& List, B. (2005), An Evaluation of Open Source E-Learning Platforms Stressing Adaptation Issues, retrieved on line March 05, 2006 from http://moodle.org/other/icalt2005.pdf

Jennings, N. R. (1998). A Roadmap of Agent Research and Development. Autonomous Agents and Multiagent Systems, 1(1), 7-38.

Koper, R. (2001). Modelling units of study from a pedagogical perspective: the pedagogical meta-model behind EML. Heerlen: Open University of the Netherlands. Retrieved November 14, 2005, from: http://eml.ou.nl/introduction/docs/ped-metamodel.pdf

Koper, R. (2004). Use of the Semantic Web to Solve Some Basic Problems in Education: Increase Flexible, Distributed Lifelong Learning, Decrease Teachers' Workload. Journal of Interactive Media in Education, 6. Retrieved November 14, 2005, from: http://www-jime.open.ac.uk/2004/6

Kuhn, T. S. (1969). La struttura delle rivoluzioni scientifiche. Turin: Einaudi.

Landauer, T. K., \& Dumais, S. T. (1997). A solution to Plato's problem: The Latent Semantic analysis theory of the acquisition, induction and representation of knowledge. Psychological Review (104), pp. 211-240.

McGuinness, D. L., \& Van Harmelen, F. (2003). OWL Web Ontology Language Overview (W3C Candidate Recommendation 18 August 2003). Retrieved November 14, 2005, from http://www.w3.org/TR/owlfeatures/

Nonaka, I., Takeuchi, H. (1995). The knowledge-creating company: how Japanese companies create the dynamics of innovation. New York (NJ): Oxford University Press.

RDF (2003). Resource Description Format (RDF). Retrieved November14, 2005, from http://www.w3c.org/RDF/

Scardamalia, M., Bereiter, C. (1996). Engaging Students in a Knowledge Society. Educational Leadership, 54 (3), pp. 6-10.

Trentin, G. (2004). Apprendimento in rete e condivisione delle conoscenze. Milan: Franco Angeli.

Varisco, B.M. (2002). Costruttivismo socio-culturale. Rome: Carocci. 
Wenger, E. (1998). Communities of Practice: learning, meaning and identity. London: Cambridge University Press.

Wenger, E. (2004), Communities of Practice a brief introduction, retrieved November 14, 2005, from http://www.ewenger.com/theory/index.htm

XML (2003). Extensible Markup Language (XML). Retrieved November 14, 2005, from http://www.w3c.org/XML/

\section{Biography}

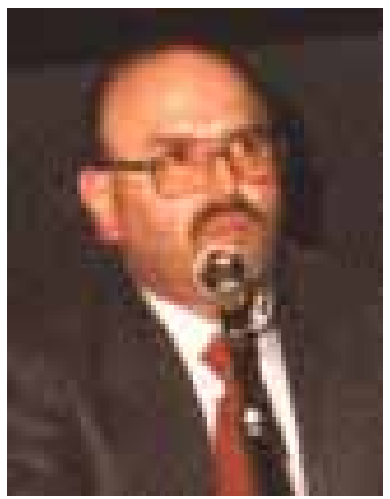

Antonio Cartelli is a researcher in Didactics. He manages the Laboratory for Teaching-Learning Technologies and the Centre for ICT and on line teaching in the Faculty of Humanities at the University of Cassino - Italy. Among his interests are: misconceptions, mental schemes, Information Systems for research and teaching, Web Technologies in teaching research and their everyday application for the improvement of teaching and learning. He is also author of many papers and books concerning the themes he is interested in. 